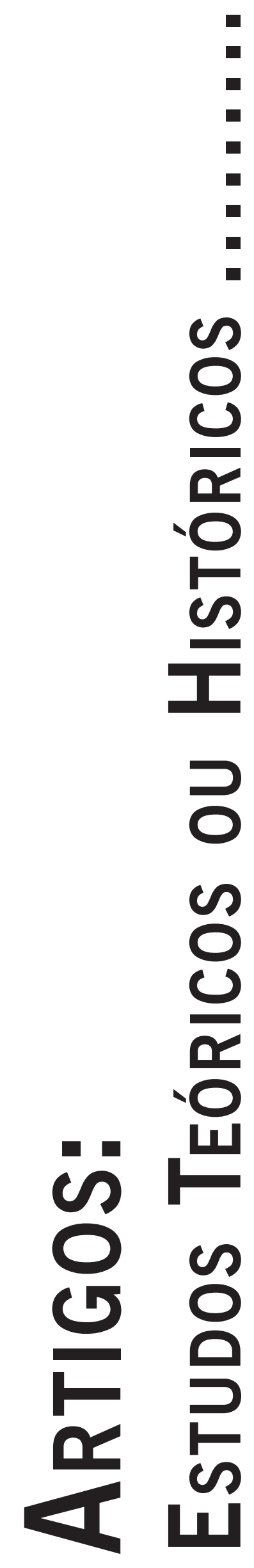




\title{
ACOMPANHAMENTO TERAPÊUTICO EM SAÚDE MENTAL: ESTRUTURA, POSSIBILIDADES E DESAFIOS PARA A PRÁTICA NO SUS
}

\author{
Therapeutic Accompaniment in Mental Health: \\ Structure, Possibilities and Challenge to its Practice in Unique System of Health \\ Acompañamiento Terapéutico en Salud Mental: \\ Estructura, Posibilidades y Desafíos para la Práctica en el Sistema Unico de Salud
}

\begin{abstract}
Resumo: O campo da Saúde Mental experiencia atualmente uma intensa revisão teórico-prática e, como desdobramentos, novos equipamentos e propostas terapêuticas vêm tomando corpo pragmático. O Acompanhamento Terapêutico (AT) insere-se neste contexto destinando ações das mais diversas ordens para proporcionar acompanhamento às diferentes demandas dos indivíduos com transtorno mental e ao resgate de sua subjetividade. Como fruto analítico da experiência de cinco anos de estruturação de uma proposta de AT junto ao estágio de saúde mental do curso de Terapia Ocupacional de uma Universidade pública Brasileira e das reflexões decorrentes de experiências na Psicologia, o trabalho que se apresenta intenciona subsidiar a estruturação do AT junto ao campo da saúde mental, especificidade dada aos serviços vinculados ao SUS. Formas estratégicas para a captação de recursos humanos, possibilidades organizativas para sua prática e elucidações quanto à potência do AT tornam-se, logo, vigas mestras da contribuição aqui pretendida.
\end{abstract}

Palavras-chave: Saúde Mental. Terapia Ocupacional. Acompanhamento Terapêutico. Saúde Coletiva. Subjetividade.

\begin{abstract}
The field of Mental Health currently experiences an intense theoretical and practical review and, as developments, new equipment and therapeutic approaches are taking place. Therapeutic Accompaniment (AT), into this context, proposes various actions to provide follow-up to the different demands of individuals with mental disorders and the rescue of their subjectivities. As an analytical result of a 5 years experience in structuring AT proposed by Occupational Therapy course at an public University in Brazil and reflections resulting from experiments in psychology, this work aims to provide subsidies for structuring the AT in Mental Health field, specificity applied to SUS' services. Strategic ways to raise funds and human resources, organizational possibilities for its practice and elucidations of the AT' potentials become, thus, the girders of this paper's intended contributions.

Keywords: Mental Health. Occupational Therapy. Therapeutic accompaniment. Public Health. Subjectivity.

Resumen: El campo de la Salud Mental actualmente vivencía una intensa revisión teórico-práctica y, como desarrollos, nuevos equipos y enfoques terapéuticos están en estructuración. El Acompañamiento Terapéutico (AT) se inscribe en este contexto proponiendo acciones de varias órdenes para proporcionar seguimiento a diferentes demandas de personas con trastornos mentales y el resgate de su subjectividad. Como resultado del análisis de 5 años de la experiencia en AT propuesto por el curso de Terapia Ocupacional de una Universidad publica Brasileña y de las reflexiones resultantes de experiencias en la Psicología, el trabajo que se presenta pretende ofrecer subsidios para la estructuración del AT junto al campo de la salud mental, con enfoque en el SUS. Maneras estratégicas para recaudar recursos humanos, posibilidades de organización para su práctica y aclaraciones acerca de la potencia del AT hacense, luego, vigas de la contribución aquí prevista.

Palabras-clave: Salud Mental. Terapia Ocupacional. Acompañamiento terapéutico. Salud Pública. Subjectividad.
\end{abstract}

\section{Introdução}

Em dezembro de 2011, o Ministério da Saúde anunciou, por meio da portaria 3.088, a Rede de Atenção Psicossocial (RAPS), configurada para proporcionar acompanhamento comunitário a pessoas com transtorno mental. A RAPS reafirmou em sua estrutura alguns equipamentos já socialmente instaurados e inseriu em seu escopo institucional algumas experiências que vinham logrando êxito em âmbito nacional (Brasil, 2011a).
Em sua proposta basal, intervenções singulares passariam a se dar de acordo com as demandas dos usuários, familiares e coletivos, procurando enfrentar problemáticas que compõem complexo quadro psicossocial e afetam, consequentemente, a população alvo da Saúde Mental em sua relação comunitária (Brasil, 2011b). Neste contexto, tanto uma série de equipamentos como toda uma gama de propostas terapêuticas vêm sendo inauguradas, embora muitas vezes a passos lentos, vivenciando uma revisão criativa de seus conceitos e práticas. Não nos abstemos 
dos exemplos: equipes de Consultório na Rua, Centros de Atenção Psicossocial, Serviços Residenciais Terapêuticos, Unidades de Acolhimento, Centros de Convivência, Grupos de Convivência e Geração de Renda, Grupos de Direitos Humanos e Controle Social, Acompanhamento Terapêutico entre outros (Lopes \& Leão, 2002; Fonseca, 2008; Ferro, Cardoso, Fedato \& Fracaro, 2012). Todos estes exemplos representam, antes de tudo, um passo importante na direção da revisão de padrões e modos tradicionais de se "ver", perceber e lidar com a "loucura", a "doença mental" e com a experiência da saúde mental.

Tomando o foco intencionado ao presente manuscrito, o Acompanhamento Terapêutico (AT) insere-se neste quadro de maneira bastante profícua. Embora com a atuação não restrita à Saúde Mental, o AT se instaura de maneira orgânica às propostas do campo (Pitiá \& Furegato, 2009; Estellita-Lins, Oliveira \& Coutinho, 2009; Ribeiro, 2009; Acioli Neto \& Amarante, 2013; Disconsi, Cavedon, Greff, Chassot, Galvão, Leães \& Carvalho, 2013). Em sua configuração, o AT propõe

[uma] atenção pormenorizada e próxima aos usuários e suas diferentes demandas. Frente à padronização das ações em saúde (...), o AT instaura-se de maneira crítica para compor ações singulares voltadas às demandas dos indivíduos e de seus familiares. A área de atuação do AT é maleável e mutante, essência fundamental de sua prática. O AT circula pela cidade, atravessa serviços de saúde, de lazer, de cultura, moradias, para encontrar e responder ao que lhe é mais imprescindível e caro - as demandas do usuário. (Ferro et al, 2014, p. 610)

Contudo, embora tanto a prática como a produção intelectual sobre o dispositivo AT apresente substancial crescimento nas últimas décadas, a organização metodológica para sua estruturação no SUS ainda necessita de contribuições mais adensadas (Benatto, 2014). Nesta vertente, é intenção do material que se apresenta proporcionar reflexões críticas que possam subsidiar a implantação e organização do AT no cotidiano dos serviços de Saúde Mental do SUS. Para tanto, o relato da experiência de cinco anos dos docentes envolvidos na estruturação da proposta de AT junto ao estágio de saúde mental do curso de Terapia Ocupacional da Universidade Federal do Paraná (UFPR) proporcionará aporte ao ensaio aqui pretendido.

\section{Acompanhamento Terapêutico: conceito, história e contribuições ao campo da Saúde Mental}

Embora historicamente com diferentes denominações, amigo qualificado, atendente terapêutico, atendente psiquiátrico, auxiliar psiquiátrico, acompanhante terapêutico, propostas de acompanhamentos próximos e singulares que transbordavam os limites físico-institucionais foram estimuladas pelos ideais das reformas psiquiátricas (Nogueira, 2009; Benatto, 2014).

$\mathrm{O}$ uso de agentes que não ficavam atuando apenas dentro do hospital, e que ainda não tinham sido batizados de "acompanhantes terapêuticos", começou a ficar potencializado, juntamente às novas experiências que estavam sendo gestadas no campo da saúde mental. A prática das atividades terapêuticas dentro do hospital e também fora das comunidades terapêuticas ganhou um novo impulso a partir das propostas da reforma psiquiátrica que teve início em alguns países da Europa. Félix Guattari (1992) escreveu sobre as suas experiências institucionais ainda na década de 1950, na Clínica de La Borde, na França, o mesmo acontecendo com Franco Basaglia (1982), no início da década de 1960 e, principalmente, na década 1970, na Itália. (Silva \& Silva, 2006)

Em contexto Latino-Americano, um movimento crítico quanto ao modelo manicomial na Argentina da década de 1960 proporcionou terreno para a edificação da prática do AT (Pulice, Manson \& Teperman, 2005). As primeiras referências ao uso do termo Acompanhamento Terapêutico

(...) ocorrem na Argentina, na clínica do Dr. Eduardo Kalina, conhecida por CETAMP - Centro de Estudos e Abordagem Múltipla em Psiquiatria. Também nesta clínica, em 1985, surge o primeiro livro publicado sobre o tema, intitulado Acompañantes Terapéuticos y pacientes psicóticos, escrito pelas psicólogas Susana Kuras de Mauer e Silvia Resnizky, que consiste em um manual introdutório e sistematizador do acompanhamento terapêutico e foi traduzido no Brasil em 1987. (Benatto, 2014, p. 8)

Ainda, o embrião do que viria a se constituir como acompanhamento terapêutico pôde ser evidenciado no Brasil nos anos de 1960 e 1970.

O acompanhamento terapêutico foi introduzido no Brasil sob a denominação de "atendente psiquiátrico", na Clínica Pinel em Porto Alegre, nos anos 60 e 70 (Berger, Moretin \& Braga Neto, 1991). Posteriormente foram encontrados registros de uma segunda experiência, no final da década de 60 no Rio de Janeiro, na Clínica Villa Pinheiros, sob a denominação de "auxiliar psiquiátrico", com forte embasamento psicanalítico. Nessa mudança de nomenclatura - passando de atendente psiquiátrico a auxiliar psiquiátrico - as funções deste profissional mantêm-se inalteradas, assim como o foco de atendimento, visto que a clínica de Porto Alegre - primeira experiência - serviu de base de inspiração para a clínica do Rio de Janeiro - segunda experiência. (Benatto, 2014, p. 8-9) 
A nomenclatura Acompanhamento Terapêutico, por fim, é assumida no Brasil na década de 1970 e 1980 e desde então vem configurando importante campo teórico-prático (Nogueira, 2009; Benatto, 2014). Para sua operacionalização, a proposta do AT conta com a figura do acompanhante terapêutico (at), o qual proporciona atenção que contempla as demandas singulares dos sujeitos e/ou grupos atendidos. O AT transpassa muros institucionais e, de maneira parceira, participa de problemáticas intrinsecamente ligadas ao cotidiano dos usuários procurando criativamente estratégias de enfrentamento (Ribeiro, 2009).

Em contraposição à suposição da neutralidade do terapeuta como condição sine qua non para o tratamento, o Acompanhamento Terapêutico impõe ao profissional o desafio de colocar em cheque seu conhecimento e imergir, junto com usuário, em um campo vivencial para intervenções criativas que possam responder de maneira resolutiva às dificuldades na relação do usuário com o seu meio comunitário.

A angústia de fazer uma clínica com pouquíssimos enquadres possibilita que os acompanhantes sejam mais desprendidos de sua técnica, utilizando-a apenas na medida do necessário. Na verdade, a técnica parece ser criada em consonância com as exigências de cada acompanhamento, tornando-a tributária da experiência clínica, e não um conjunto rígido de regras que aprisionem acompanhante e acompanhado em um modelo a ser seguido, sem que a singularidade do que ali aconteça seja levada em consideração. (Ribeiro, 2009, p. 80)

Em diálogo com o atual campo discursivo da Saúde Mental, o AT destaca-se enquanto dispositivo ímpar para a composição de possibilidades de intervenção junto às problemáticas cotidianas do usuário, aliando e posicionando ações que conjuguem de maneira intrínseca, orgânica e estratégica dificuldades e potencialidades individuais, familiares e comunitárias (Freitas, 2013; Gerab \& Berlinck, 2013).

O dia-a-dia, o contexto familiar, social, o lazer, vistos de dentro da realidade cotidiana vivenciada nos atendimentos sinalizarão os caminhos a serem percorridos, os objetivos a serem traçados e o término do trabalho, constituindo um impulso para a reconstrução de uma autonomia de base e para a plena utilização dos recursos e potenciais disponíveis no cotidiano do paciente. Trata-se de reabilitação enquanto reconstrução da existência. Esta reconstrução solicita rotinas e ritmos. As necessidades psicossociais específicas dos pacientes em reabilitação determinam esta reconstrução, como a capacidade de lidar com problemas cotidianos, desenvolvimento de auto-estima, habilidades sociais, desenvolvimento de autonomia e prática da cidadania. (Estellita-Lins, Oliveira \& Coutinho, 2009, p. 207)

Em seu percurso comunitário com o usuário, o AT experiencia a concretude em sua face mais nua, dessintonizando a prática do consultório para a assunção de uma clínica da alteridade.

O AT é prática de trocas em que os intercâmbios sociais estão na base dos acontecimentos construídos nos atendimentos. Da mesma forma, é prática interdisciplinar sem demarcações territoriais de saberes ou excesso de identidades (...). O AT promove a saúde no mais aberto dos espaços, transita pela cidade e apropria-se dela como lugar de habitação e convivência coletiva, campo de negociações e de exercício de contratualidade social e cidadania. (Fiorati \& Saeki, 2008, p. 766)

Embora ao dispositivo seja imprescindível a manutenção de sua mobilidade e permeabilidade frente aos processos de vida do acompanhado na conjugação entre objetivos terapêuticos e intervenções, suas ações devem organizar-se de maneira sistemática para ampliação de sua potência e para proporcionar enfrentamento efetivo das problemáticas evidenciadas. É neste sentido que o presente trabalho pretende tecer contribuições teórico-práticas para o campo do Acompanhamento Terapêutico.

\section{Acompanhamento terapêutico: entre possibilidades, recursos humanos e afirmação da desigualdade}

Embora o Acompanhamento Terapêutico proporcione inegável contribuição para o desenvolvimento de projetos terapêuticos no campo da saúde mental, a sua estruturação apresenta diferentes problemáticas. A primeira delas diz respeito à sua implantação.

Em diálogo com diferentes gestores de equipamentos de saúde mental, uma barreira sempre evidenciada para a prática do AT é a dificuldade na obtenção de recursos humanos. Como um gestor de um Centro de Atenção Psicossocial (CAPS) pode, por exemplo, dedicar 1, 2, 3, horas semanais de um de seus profissionais para acompanhar de maneira próxima somente um usuário? Como empreender, com recursos humanos limitados, a proposta do AT e, com isso, ampliar as possibilidades de cuidado comunitário aos usuários dos serviços de saúde mental?

Distante de assumir a potência do dispositivo de maneira romantizada, interessa-nos discutir algumas das problemáticas de sua implementação inseridas no contexto capitalista que lhe subjaz; afinal, o fato é que famílias com maior aporte de recursos financeiros podem organizar-se para contratar profissionais, muitas vezes pós-graduados, para pragmatizar tal empreitada. Como se daria, contudo, 
tal prática no SUS? Cabe-nos, como pesquisadores e docentes de uma Universidade Pública pensar de maneira estratégica algumas formas de operacionalizar o AT no âmbito do SUS, bem como a aproximação entre ensinoserviço, considerando as Diretrizes Curriculares Nacionais que apregoam a formação de profissionais para o SUS.

Reconhecidamente, a maioria dos programas de Acompanhamento Terapêutico no SUS estão vinculados a Universidades (Nogueira, 2009; Silva, Costa \& Neves, 2010; Benatto, 2014). Em diferentes experiências retratadas pela literatura, o AT toma corpo por meio de práticas vinculadas a estágios obrigatórios ou projetos de extensão - nossa experiência junto ao dispositivo na Universidade Federal do Paraná reafirma tal quadro.

Embora seja incontestável a afirmação da importância do vínculo longitudinal entre AT e usuário para a concisão das propostas terapêuticas (Maia, 2006), as iniciativas pautadas em estágios obrigatórios apresentam a limitação própria ao período letivo (Nogueira, 2009; Ferro et al., 2014). No curso de Terapia Ocupacional, por exemplo, os estágios obrigatórios são semestrais e localizados temporalmente em 4 meses, o que impõe certas limitações na experiência de utilização do dispositivo. O mesmo acontece com os estágios do curso de Psicologia da UFPR.

Atualmente os departamentos de Terapia Ocupacional, Psicologia e Enfermagem da UFPR estruturaram, em parceria com a prefeitura de Curitiba, um programa de extensão que prevê, enquanto uma de suas ações, a prática do AT. Embora o programa tenha sido composto de maneira a contornar algumas das limitações temporais próprias à configuração do estágio, a barreira ainda é presente - a vinculação do estudante ao programa, seja por meio de bolsa ou voluntariamente, apresenta circunscrição de 1 ou, ao máximo, 2 anos.

Procurando ampliar a especialização dos profissionais no exercício do AT, possibilidades estratégicas podem se constituir no estabelecimento de parcerias institucionais com cursos de pós-graduação em Acompanhamento Terapêutico. Nesta vertente, a concessão de campo de prática para o AT pode, por um lado, garantir tanto duração temporal mais prolongada como maior especialização das ações dos ats. Outra possibilidade que poderia se apresentar para a implantação do Acompanhamento Terapêutico no âmbito da Saúde Mental do SUS é a configuração de cursos de AT vinculados aos equipamentos de Saúde Mental, os quais, ao proporcioná-los, garantiriam por um lado formação profissional para o AT e, por outro, campo de prática para seus usuários.

Embora o dispositivo seja de imprescindível valor ao campo da Saúde Mental (mesmo que não somente a este), sua inserção encontra-se relacionada de maneira orgânica ao contexto econômico, político e social que imprime, neste panorama, substanciais variações qualitativas para a população atendida pelo SUS. A figura 1 apresenta algumas das possibilidades de captação de recursos humanos para a prática do AT.

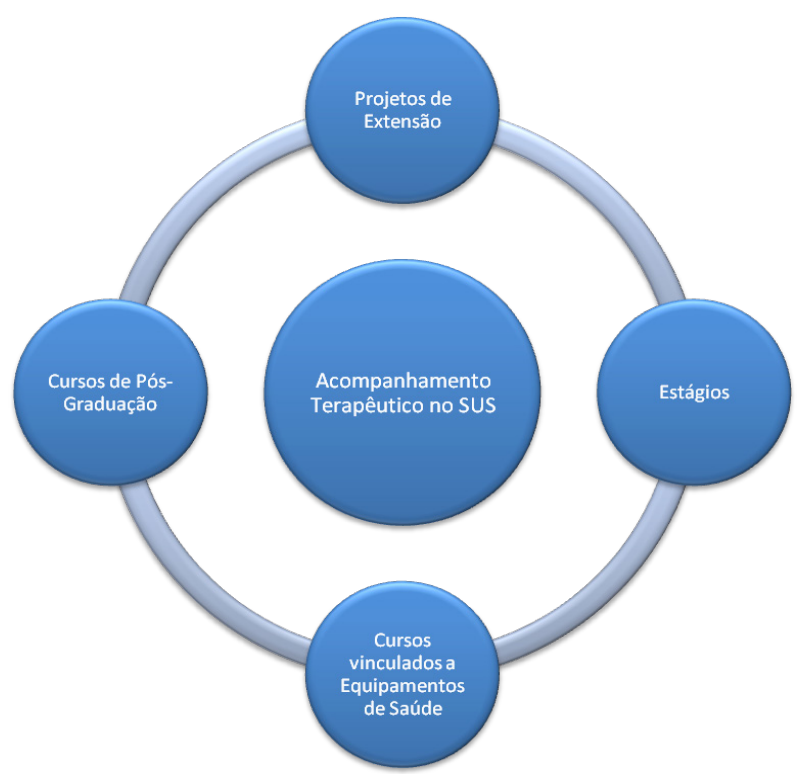

Figura 1: Possibilidades de captação de recursos humanos para a prática do Acompanhamento Terapêutico

\section{Acompanhamento terapêutico e estruturação de ações em saúde mental: entre desencontros e potência}

A partir da apresentação de algumas das possibilidades de captação de recursos humanos para a estruturação da prática do Acompanhamento Terapêutico, foco dado aos serviços de saúde mental do SUS, cabe a elucidação de algumas problemáticas que vivenciamos nestes 5 anos de implantação do dispositivo para, em seguida, elaborarmos analiticamente algumas possibilidades de (re) organização do trabalho.

Como acima registrado, o AT, na experiência que queremos aqui apresentar, está vinculado ao estágio curricular em Saúde Mental do departamento de Terapia Ocupacional da Universidade Federal do Paraná, com exercício da prática em um dos CAPS parceiros da região. Inicialmente, reservamos carga horária semanal para a prática do Acompanhamento Terapêutico no estágio semestral, contudo evidenciamos naquele momento algumas dificuldades.

Em alguns momentos desta experiência, os usuários eram apresentados aos estudantes sem definição precisa de suas ações, mesmo com tentativas consecutivas dos docentes supervisores de alinhamento com a equipe, o que, na prática, cerceava a potência do dispositivo. A limitação temporal do AT, já apontada como problemática em outras experiências (Nogueira, 2009), aprofundava-se aqui. Para além, muitas vezes, era sensível certa dificuldade dos profissionais responsáveis pelo caso, no estabelecimento do Projeto Terapêutico Singular ${ }^{1}$ (PTS), o que

\footnotetext{
O PTS, previsto pela atual política pública de Saúde Mental, constitui-se como guia para o desenvolvimento das ações em Saúde, estabelecendo e direcionando intervenções singulares e processuais, sejam individuais ou coletivas, de maneira intersetorial. Para maior aprofundamento, consultar OLIVEIRA (2007) e Miranda, Coelho e Moré (2012).
} 
adicionava uma frouxidão às ações e processo terapêutico, e deixava o estagiário sem os recursos necessários para a elaboração de ações úteis ao desenvolvimento do PTS do usuário

Novas informações e possibilidades estratégicas de intervenção, neste contexto, permaneciam adormecidas frente à insegurança de alguns estudantes em aplicá-las de maneira solitária e sem apoio próximo da equipe do
CAPS. Outros estudantes, por vezes, realizavam ações de maneira impulsiva e que, no decorrer do estágio, demonstraram complexa repercussão. Neste contexto, toda uma nova lógica de funcionamento e um outro desenho programático passou, ao menos em nossa experiência, a ser imprescindível para a estruturação/ampliação da potência do AT. O fluxograma que se segue, explicita sua configuração.

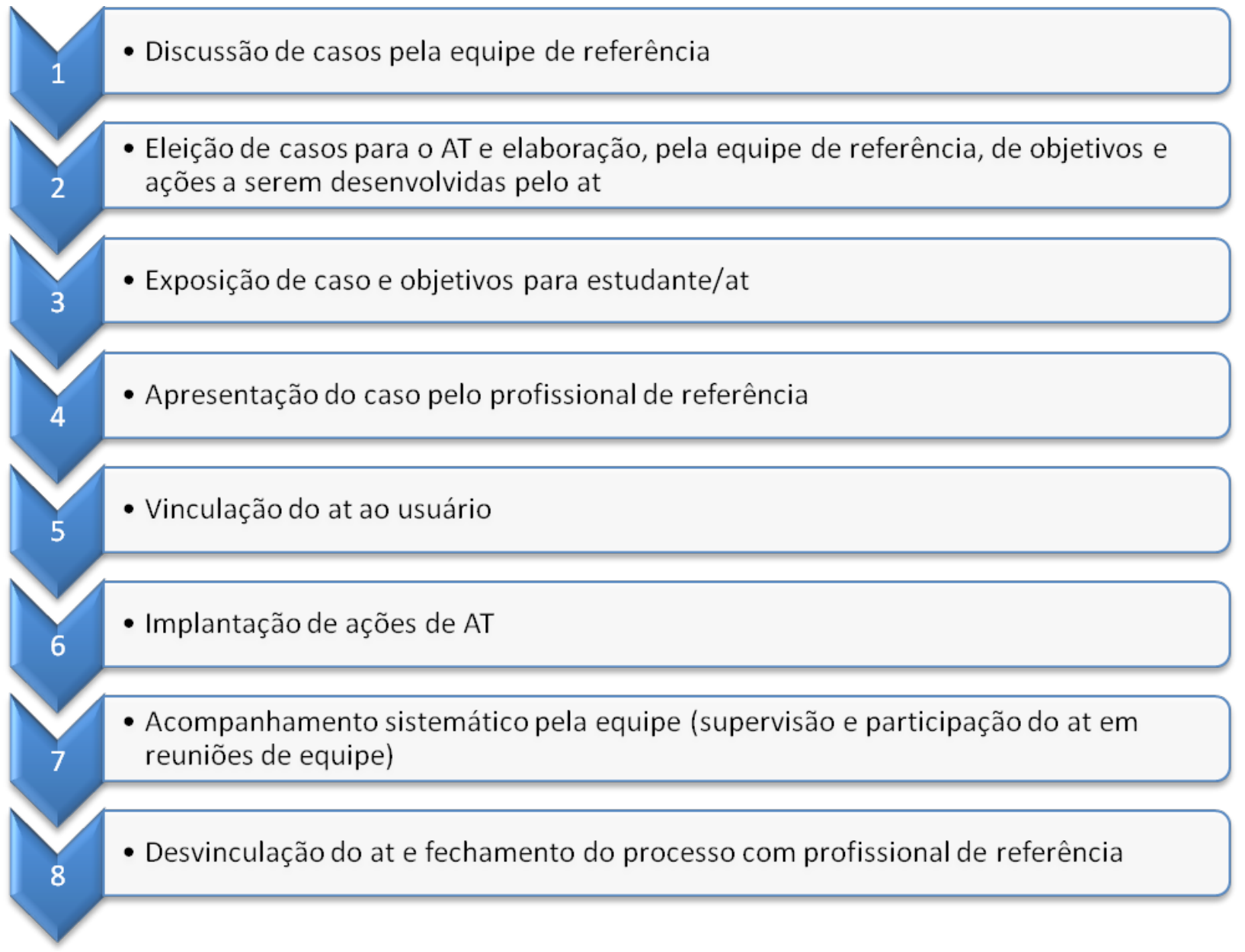

Fluxograma 1: Estruturação para a prática do AT no campo da Saúde Mental do SUS

Contraste nítido: se o AT for desenvolvido por um dos profissionais com graduação concluída e especialização no dispositivo, contratado sem limitações temporais, é inevitável a assunção de diferentes responsabilidades por tal profissional na elaboração e execução de variadas ações terapêuticas. Contudo, o AT, se reservado à incipiência do trabalho de estudantes em período de estágio curricular, de 15 semanas da formação sua potência certamente é subaproveitada.

No primeiro, segundo e terceiro passos do fluxograma acima exposto, a defesa argumentativa é que os profissionais possam reunir-se para discussão e eleição de casos que mais se beneficiariam do dispositivo, haja vista a impossibilidade estrutural do fornecimento indistinto do AT no SUS 2 .

Nestas oportunidades, tais profissionais elaborariam objetivos mais circunscritos, advindos de sua maior propriedade dos casos, que pudessem reverter em ações que contribuiriam para movimentar determinados Projetos Terapêuticos Singulares ligados aos usuários. Desta forma, o estudante, no momento do ingresso no AT junto ao estágio, poderia em breve momento e com o acompanhamento do

\footnotetext{
Reafirma-se aqui a necessidade do vislumbre para conduzir de maneira madura à elaboração de necessárias ações sociais de enfrentamento e à proporção da equidade prevista, por meio da contratação de recursos humanos
} 
técnico de referência, inteirar-se do caso e ter orientações claras sobre ações e objetivos, já previamente elaborados pela equipe de referência. A explanação a respeito dos casos e estratégias, neste contexto, poderia se dar pela figura do técnico de referência ou mesmo do supervisor do campo de estágio à ocasião do ingresso do estudante.

A elaboração do item 4 poderia, por sua vez, proporcionar estrutura à produção qualitativa e temporalmente maximizada de vínculo entre AT e acompanhado e, com isso, aligeirar a implantação de ações. Em porte de ações já bem definidas pela equipe de referência do usuário, em conjugação orgânica com seu PTS, e com vínculo potencializado, o AT em curto espaço poderia passar a desenvolver as intervenções que lhe coubessem. "Versatilidade, mobilidade e a disposição para o imprevisto e para o improviso, não como se tais fossem acontecimentos extraordinários, mas considerando-se que, nessa clínica, os mesmos fazem parte do dia-a-dia” (Ribeiro, 2009, p. 81).

À prática do AT é inevitável o fio da navalha. O AT é e deve possuir a fluidez que lhe é própria, contudo acreditamos que os guias para as ações se por um lado devem ser bem planejados, por outro devem enxergar e dar vazão aos processos vitais de cada usuário, sempre em constante mutação. Tal fluxo deve encontrar respaldo estrutural na prática do AT, para isso, tanto equipe, quanto profissional de referência e supervisor de estágio devem possuir espaço de escuta do processo colocado em andamento.

Espaços de discussão dos casos, seja na forma de supervisão, de conversas com profissional de referência, da participação nas reuniões de equipe, são fundamentais para proporcionar a sustentação para tal escuta. No fluxograma, estas aberturas, previstas no item 7, podem permitir a porosidade necessária ao AT, possibilitando reconfigurar, ao decorrer do processo, tanto intervenções quanto objetivos. A instituição destas estruturas permite, ainda, proporcionar maior segurança ao estudante na (re) elaboração e implantação de ações terapêuticas.

Uma das problemáticas vivenciadas junto ao AT diz respeito ao processo de desvinculação do estudante e do usuário. Um vínculo próximo com o usuário necessita da devida distinção entre o aspecto profissional e o vínculo de amizade para que, no momento do desligamento, tanto usuário como estudante não se mostrem resistentes. Pois bem, a experiência permitiu-nos amadurecer em vários dos aspectos já enunciados e, com maior especificidade, no último item do fluxograma 1. A chance de tais riscos apresentarem-se ao usuário e/ou família que contrata serviços de profissionais mais especializados é mais baixa incontestavelmente. Contudo, para a prática do AT em serviços públicos, foco aqui dado aos vinculados ao campo da saúde mental, é necessária a elaboração de algumas estratégias.

Se todo um processo da prática do AT estiver melhor desenhado, contando com momentos de supervisão, concretude e clareza de objetivos e ações terapêuticas, além de contato próximo com a equipe, a minimização de tais riscos tende a ser observada. Contudo, acreditamos que se o processo de desvinculação puder ser trabalhado pelo profissional de referência, pontuando tanto para estudante como para usuário tal desligamento e reforçando as positividades advindas do dispositivo e o vínculo mais duradouro do usuário com a equipe de referência, tal processo pode contribuir para minimizar ainda mais tais arestas e, com isso, potencializar os benefícios do dispositivo AT.

Acreditamos que neste ponto, o processo de "transmissão do vínculo", se é que se poderia assim denominar o processo de passagem da responsabilidade da tarefa de um estagiário para o outro, poderia minimizar os riscos deste desligamento e fortalecer o estabelecimento de vínculo com o novo AT ou estagiário. Este processo tem sido utilizado em outros campos de estágio de Saúde Mental como forma de atenuar a quebra sistemática de vinculo a cada quatro meses, para estabelecimento de novo vínculo que previamente já se sabe que durará outros quatro meses. Ao longo do tempo o usuário acaba se "acostumando" e parece que o vínculo fica mais focado nos objetivos e na função do estagiário/AT do que propriamente na pessoa, com a consciência de que as figuras permanentes são o supervisor e o professor orientador.

\section{Acompanhamento Terapêutico e Saúde Mental: Possibilidades do dispositivo}

Para além de configurações institucionais que possam potencializar e estruturar a prática do Acompanhamento Terapêutico, algumas considerações sobre as possibilidades de contribuição do dispositivo para o campo da Saúde Mental do SUS ainda necessitam de maior aprofundamento.

A atenção singularizada e próxima, propiciada pelo Acompanhamento Terapêutico, conjugada com sua flexibilidade de intervenções e liberdade de transpor espaços físico-institucionais, se permite, por um lado, a implantação de ampla gama de ações terapêuticas, por outro configuram algumas barreiras para sua prática no SUS. Ao AT, como já explicitado, é mister o destino de suas ações para responder às demandas apresentadas pelos acompanhados. E, ao assumir a mobilidade do dispositivo, suas intervenções possíveis podem ter emprego da mais variada sorte.

Sob nosso ponto de vista, portanto, o AT constitui instrumento importante para integrar projetos centrados em um modo de atenção psicossocial, pois ambos: estabelecem práticas que se opõem às formas manicomiais de tratamento e alinham-se às propostas da reforma psiquiátrica; compõem ações de resgate da contratualidade como cidadão; representam formas de cuidado que se apóiam na singularização do sujeito, na medida em que implica o indivíduo em sua dimensão subjetiva, sociocultural e histórica; são práticas 
de trocas, pois os intercâmbios sociais estão na base das construções e acontecimentos possíveis, e constituem práticas interdisciplinares, sem demarcações de territórios e fragmentação dos saberes e práticas. (Fiorati \& Saeki, 2008, p. 767)

Se o AT pode ser utilizado para acompanhar o usuário em seu percurso vital, auxiliando-o na composição companheira de um cotidiano mais salutar, suas ações não precisam necessariamente ter foco exclusivo no acompanhado. $\mathrm{O}$ acompanhamento individualizado do caso permite intervir, ao aprofundar-se, em diferentes fatores que influenciam de maneira substancial o processo de saúde do usuário. O foco das ações do AT podem se dar, em determinado momento, na família ou em determinados componentes da rede social de apoio do usuário.

Para além disso, embora muito da atuação do AT seja reservado a intervenções fora de muros institucionais, em determinado momento o AT pode realizar o acompanhamento no "intramuros". Caso o usuário seja internado em momento de crise, por exemplo, o AT pode deslocar seu atendimento para analisar possibilidades de suporte ao usuário no espaço do hospital psiquiátrico ou mesmo para a equipe profissional da instituição, ampliando a efetividade do tratamento e sua conjugação com os objetivos de seu PTS. Ainda, como acima citado, há a oportunidade do destino de suas ações para outros membros da Rede Social de Apoio do usuário.

Em adição, a possibilidade da relação do AT com outros equipamentos da rede de serviços, pode facultar a aproximação e ampliar a dialogicidade entre o serviço de saúde de referência (em nosso caso, o CAPS) e outros pontos da rede, contribuindo sobremaneira para o exercício do trabalho em rede. Encaminhamentos de usuários a determinadas instituições, muitas vezes sem qualquer resolução e transformação de seu cotidiano, poderiam ser acompanhados de perto pelo AT, tecendo parcerias e pontes institucionais que maximizariam a potência do trabalho em rede e reverteriam, inquestionavelmente, para a edificação de projetos de vida dos sujeitos atendidos pelos serviços de saúde mental.

O AT pode, ainda, configurar ações para levantamento de possibilidades territoriais para enfrentamento de determinadas problemáticas vivenciadas pelo usuário: associações, tratamento para hipertensão, grupos de convivência, possibilidades de trabalho, lazer, esporte, etc.

Para além, algumas informações sobre os usuários, seu processo de saúde-doença, relações pessoais ou com seu território, muitas vezes permanecem sombreadas para a equipe de referência de um determinado serviço de saúde. A prática do AT pode ser destinada a realizar aprofundamento em determinados casos para que informações aprofundadas e fidedignas possam ser coletadas para auxiliar a equipe de referência a elaborar determinadas intervenções terapêuticas.
Em suma, o trabalho junto ao AT é e deve ser fluido e criativo, pautado nas diversas transformações vitais que possam permear a vida do usuário, sua família e sua comunidade/território. A figura 2, sem a intenção de restringir as possibilidades criativas das ações do AT, é destinada a esquematizar algumas das possibilidades proporcionadas pelo dispositivo.

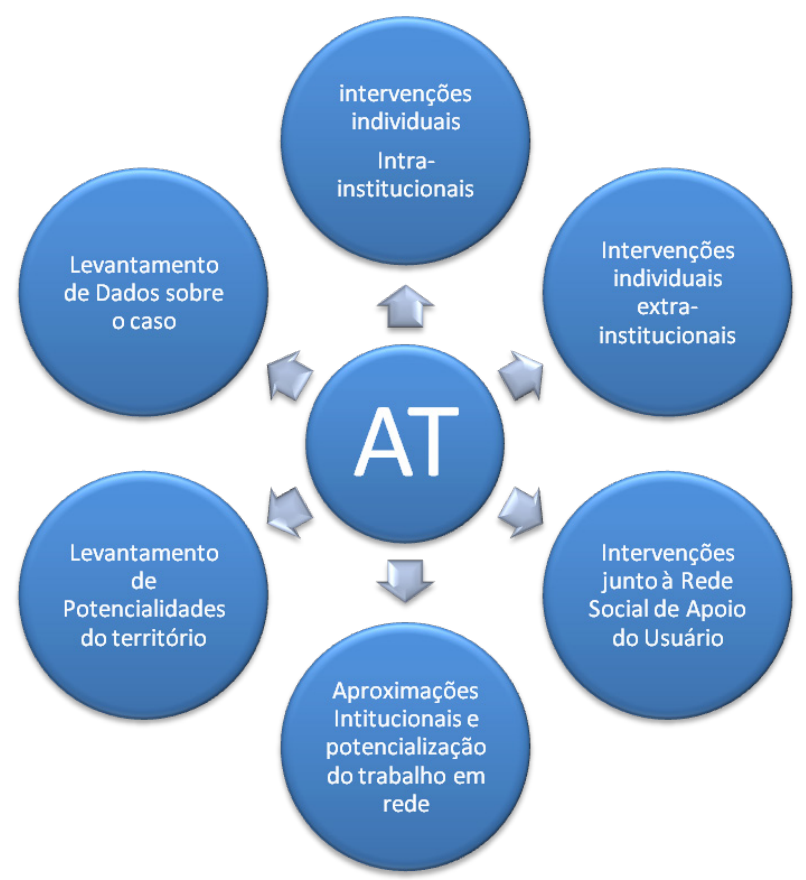

Figura 2: Possibilidades de ações vinculadas ao Acompanhamento Terapêutico

\section{Considerações finais}

No manuscrito aqui apresentado, para além da assunção abrilhantada do AT enquanto profícuo dispositivo, nos interessou explorar algumas de suas dificuldades e possibilidades estratégicas para a organização de sua prática no SUS, foco dado neste momento ao campo da Saúde Mental.

Da captação possível de recursos humanos, da elaboração analítica de possibilidades de estruturação de sua prática ao levantamento de suas potencialidades singulares, pretendeu-se aqui colaborar para a reflexão sobre o dispositivo e sua implantação.

A assunção da diferença entre a prática do AT em âmbito privado e público proporciona o aparecimento de terrenos singulares, os quais exigem estratégias que dialoguem com o atual cenário social na busca de, ao menos, diminuir criativamente algumas das limitações evidenciadas. Tais buscas, contudo, reafirmam cotidianamente as diferenciações sociais impostas pela situação do dispositivo dentro de um contexto capitalista. Para enfrentar as diferentes dificuldades para a implantação e organização do AT, neste manuscrito apresentadas, por certo uma estratégia seria a contratação de mão-de-obra mais 
especializada, que apresentasse vinculo/condições trabalhistas que proporcionassem ações técnicas que perdurassem longitudinalmente, e é nesse sentido que as diferenciações se apresentam.

Perguntas críticas, aqui inevitáveis, surgem: até quando agentes vinculados à saúde, como os autores que assinam este manuscrito, necessitarão elaborar propostas, funcionamentos e formas alternativas para procurar potencializar práticas do SUS, neste caso a do AT, assumindo as limitações estruturais dos serviços públicos de saúde? Quando, dentro dos serviços públicos, conseguiremos um número adequado de profissionais para este tipo de atendimento? Quando será possível falar veementemente em equidade nos serviços de saúde? Ademais, parece-nos que o AT, como dispositivo plenamente passível de realização, situa-se no entremeio de práticas clínicas tradicionais e de outras inovadoras, mas que certamente sua atuação pode - e deve - ser vista como uma alternativa tanto para a prevenção, quanto para o acompanhamento de situações que demandam sobremaneira, de um serviço que invariavelmente padece de condições ditas "adequadas". Neste sentido, o AT surge não como uma prática concorrente, mas mesmo como a possibilidade da efetivação de um tratamento verdadeiramente concreto, objetivo e humanizador no campo da Saúde Mental.

\section{Referências}

Acioli Neto, M. L. \& Amarante, P. D. C. (2013). O Acompanhamento Terapêutico como estratégia de cuidado na atenção psicossocial. Psicologia: Ciência e Profissão, 33 (4), 964-975. <https://dx.doi.org/10.1590/S1414-98932013000400014>.

Benatto, M. C. (2014). A clínica do acompanhamento terapêutico no Brasil: uma análise da produção científica de 1985 a 2013. Dissertação (mestrado). Pós-graduação em Psicologia, Universidade Federal do Paraná, Curitiba.

Brasil (2011b). Guia prático de matriciamento em saúde mental. Brasília: Ministério da Saúde. Disponível em: <http:/ www.aadom.org.br/materiais-de-apoio/assistencia-em-saude-mental> .

Brasil (2011a). Portaria $n^{\circ}$ 3.088, de 23 de dezembro de 2011 Brasília: Ministério da Saúde. Disponível em: <http:// www.aadom.org.br/materiais-de-apoio/legislacao-em-saude-mental>.

Disconsi, A. M., Cavedon, B. Z., Greff, B. P., Chassot, C. S., Galvão, C., Leães, M. L., \& Carvalho, M. G. (2013). Acompanhamento terapêutico: andanças pelo dentro e o fora da instituição. Psicologia $\&$ Sociedade, 25 (n. spe. 2), 65-72. https:// dx.doi.org/10.1590/S0102-71822013000600009>.

Estellita-Lins, C.; Oliveira, V. M. \& Coutinho, M.F . (2015). Clínica ampliada em saúde mental: cuidar e suposição de saber no acompanhamento terapêutico. Ciência $\&$ Saúde Coletiva (Rio de Janeiro). 14 (1), 205-215. <http://dx.doi.org/10.1590/ S1413-81232009000100026>.
Ferro, L. F., Cardoso, M. M, Fedato, G. \& Fracaro, C. C. (2012). Grupo de Convivência em Saúde Mental: perspectivas de usuários e a experiência do curso de Terapia Ocupacional da Universidade Federal do Paraná. Revista de Terapia Ocupacional da Universidade de São Paulo (São Paulo), 23 (2), 146-152. Disponível em: <http://www.revistas.usp.br/rto/ article/view/49078>.

Ferro, L. F.; Lucindo, S. M.; Vozniack, C. I. \& Oliveira, F. R. L. (2014). Demandas, subjetividade e processo terapêutico: construções e limitações do Acompanhamento Terapêutico. Cadernos de Terapia Ocupacional UFSCar (São Carlos), 22 (3), 1-11. Disponível em: <http://www.cadernosdeterapiaocupacional.ufscar.br/index.php/cadernos/article/ view/748 >

Fiorati, R.C. \& Saeki, T. (2008). O acompanhamento terapêutico na internação hospitalar: inclusão social, resgate de cidadania e respeito à singularidade. Interface (Botucatu), 12 (27), 763-772. <http://dx.doi.org/10.1590/S1414$32832008000400007>$.

Fonseca, M. A. (2008). A Prática do Terapeuta Ocupacional em Saúde Mental a partir de uma Perspectiva não Excludente e de Respeito às Diferenças. In: A. F.Drumond \& M.B. Rezende (Org.). Intervenções da Terapia Ocupacional (p. 71-94). Belo Horizonte: Editora UFMG.

Freitas, A. P. (2013). Olhares e perspectivas do acompanhante terapêutico sobre a família do acompanhado. ATravessar: Revista de Acompanhamento Terapêutico, 1 (2), 09-18.

Gerab, C. K. \& Berlinck, M. T. (2012). Considerações sobre o enquadre na clínica do AT. Estilos da Clínica, 17 (1), 88-105.

Lopes, R. E. Leão, A. (2002). Terapeutas ocupacionais e os centros de convivência e cooperativas: novas ações de saúde. Revista de Terapia Ocupacional da Universidade de São Paulo (São Paulo), 13 (2), 56-63. Disponível em: <http://www. revistas.usp.br/rto/article/view/13897>.

Maia, S. M. (2006). O acompanhamento terapêutico como uma técnica de manejo. Psyche (São Paulo), 10 (18), 29-40. Disponível em: < http://pepsic.bvsalud.org/pdf/psyche/v10n18/ v10n18a04.pdf $>$.

Miranda, F. A. C.; COELHO, E. B. S.; MORÉ, C. L. O. O. (2012). Projeto Terapêutico Singular. Florianópolis: UFSC, 2012.

Nogueira, A. B. (2009). O acompanhamento terapêutico e sua caracterização em Betim e Belo Horizonte. Psicologia Revista (Belo Horizonte), 15 (2), 204-222. Disponível em < http://pepsic.bvsalud.org/scielo.php?script $=$ sci_arttext\&pid $=$ S1677$-11682009000200013 \& \operatorname{lng}=\mathrm{pt} \& \mathrm{nrm}=\overline{\mathrm{i}} \mathrm{so}>$.

Oliveira, G. N. (2007). O Projeto terapêutico como contribuição para a mudança das práticas de saúde. (Dissertação de Mestrado). Universidade Estadual de Campinas, Campinas.

Pitiá, A. C. A. \& Furegato, A. R. F. O. (2009). Acompanhamento Terapêutico (AT): dispositivo de atenção psicossocial em saúde mental. Interface (Botucatu), 13 (30), 67-77. Disponível em: <http://www.scielo.br/pdf/icse/v13n30/v13n30a07.pdf >.

Pulice, G. O.; Manson, F. \& Teperman, D. (2005). Acompanhamento terapêutico: contexto legal, coordenadas éticas e responsabilidade profissional. Estilos da Clínica 
(São Paulo), 10 (19), 12-31. Disponível em <http://pepsic. bvsalud.org/scielo.php?script =sci_arttext\&pid $=$ S1415$-71282005000200002 \& \operatorname{lng}=\mathrm{pt} \& \mathrm{nrm}=\mathrm{iso}>$.

Ribeiro, A. M. (2009). A idéia de referência: o acompanhamento terapêutico como paradigma de trabalho em um serviço de saúde mental. Estudos de Psicologia (Natal), 14 (1), $77-$ 83. Disponível em: <http://www.scielo.br/pdf/epsic/v14n1/ a10v14n1.pdf $>$.

Silva, A. S. T. \& Silva, R. N. (2006). A emergência do acompanhamento terapêutico e as políticas de saúde mental. Psicologia, Ciência e Profissão (Brasília), 26 (2), 210-221. https:// dx.doi.org/10.1590/S1414-98932006000200005 >.

Silva, M. V. O.; Costa, F. R. M. \& Neves, L. M. (2010). Programa de intensificação de cuidados: experiência docente-assistencial em Psicologia e reforma Psiquiátrica. Psicologia, Ciência e Profissão (Brasília), 30 (4), 882-895. Disponível em: $<$ http://pepsic.bvsalud.org/pdf/pcp/v30n4/v30n4a16.pdf>.

Luis Felipe Ferro - Graduação em Terapia Ocupacional pela Universidade de São Paulo. Mestre em Psicologia e doutor em Ciências pelo Programa de Pós-Graduação em Psicologia Social da Universidade de São Paulo - USP. Docente do Departamento de Terapia Ocupacional da UFPR. Email: luisfelipeferro@gmail.com

Milton Carlos Mariotti - Doutor em Ciências da Saúde pela UFPR. Mestre em Educação pela UFPR. Graduado em Terapia Ocupacional pela PUCCampinas. Professor Adjunto do Departamento de Terapia Ocupacional do Setor de Ciências da Saúde da Universidade Federal do Paraná (UFPR). Email: miltoncarlosmariotti@gmail.com

Adriano Furtado Holanda - Psicólogo, Doutor em Psicologia, Docente do Curso de Psicologia e do Programa de Mestrado em Psicologia na Universidade Federal do Paraná (UFPR), Coordenador do Laboratório de Fenomenologia e Subjetividade (LabFeno-UFPR) e Coordenador do Grupo de Trabalho Psicologia \& Fenomenologia na Anpep. Email: aholanda@yahoo.com

Mirian Aparecida Nimtz - Graduada em Enfermagem e Obstetricia pelas Faculdades da Zona Leste de São Paulo, Mestre em Enfermagem pela Escola de Enfermagem da Universidade de São Paulo - EEUSP e Doutora em Enfermagem pela Escola de Enfermagem da Universidade de São Paulo - EEUSP. Atualmente ocupa o cargo de Professora Adjunto da Universidade Federal do Paraná- UFPR e Professora colaboradora do Programa de Pós-Graduação em Enfermagem da Universidade Federal do Paraná (PPGENF- UFPR). Email:miriamnimtz@uol.com.br

Recebido em 24.02.2017

Primeira Decisão Editorial em 03.05.2017

Aceito em 12.07.2017 